\title{
Correction to: The Win-win Game in Politics? A Study on Student Body of the Ruling Party in Bangladesh
}

Mubammed Rashedul Hasan and Nazmul Abasan

Correction to:

Chapter "The Win-win Game in Politics? A Study on Student Body of the Ruling Party in Bangladesh" in: A. E. Ruud and M. Hasan (eds.), Masks of Authoritarianism, https://doi.org/10.1007/978-981-16-4314-9_5

The original version of the book was inadvertently published with incorrect author name in both citation and reference list in Chapter "The Win-win Game in Politics? A Study on Student Body of the Ruling Party in Bangladesh". The author's last name is corrected from "Murhid (2010)" to "Murshid (2010)". The book has been updated with the changes.

The updated version of this chapter can be found at https://doi.org/10.1007/978-981-16-4314-9_5

(C) The Author(s), under exclusive license to Springer Nature $\mathrm{Cl}$ Singapore Pte Ltd. 2022

A. E. Ruud and M. Hasan (eds.), Masks of Authoritarianism, https://doi.org/10.1007/978-981-16-4314-9_17 